\title{
POLLINATION OF GUARIANTHE SKINNERI, AN ORNAMENTAL FOOD DECEPTION ORCHID IN SOUTHERN FLORIDA, BY THE NATURALIZED ORCHID BEE EUGLOSSA VIRIDISSIMA
}

\author{
ROBERT W. PEMBERTON \\ Invasive Plant Research Laboratory \\ United States Department of Agriculture-Agricultural Research Service \\ 3225 College Ave. Fort Lauderdale, Florida 33314 U.S.A. \\ Robert.Pemberton@ars.usda.gov
}

\begin{abstract}
A Mesoamerican orchid bee Euglossa viridissima, recently naturalized in Florida, is pollinating cultivated plants of Guarianthe skinneri, also native to Mesoamerica. The flowers were found to be self compatible and nectarless. Of 25 bees observed to visit 31 G. skinneri flowers, 18 picked up pollinaria, and 17 of the bees left the plant after visiting a single flower of this food deception orchid. The bee's behavior lends support to the idea that food deception pollination systems reduce geitonogamy and promote outcrossing. Cultivated G. skinneri plants growing where the orchid bee occurs in Florida are fruiting which creates the possibility of the naturalization of this orchid. Euglossa viridissima is probably a pollinator of G. skinneri in Mesoamerica where they co-occur.
\end{abstract}

KEY WORDS: Orchidaceae, Euglossa, Guarianthe, food deception pollination, Florida.

Guarianthe skinneri (Bateman) Dressler \& W.E. Higgins is a commonly grown orchid in southern Florida. It is native to southern Mexico and Central America, south to Costa Rica (Bechtel et al. 1992) where it is the national flower. Until recently this bifoliate orchid was known as Cattleya skinneri, but molecular analyses demonstrated that the C. skinneri complex is a natural group separate from Cattleya (Dressler \& Higgins 2003). The new genus Guarianthe is derived from the Costa Rican word for orchid "guaria" as in "guaria morada" (G. skinneri), and the Greek "anthos" for flower (Dressler \& Higgins 2003, Dressler 2005). Although this orchid is frequently grown outdoors in the coastal areas of southeastern Florida where frost rarely occurs, it did not, apparently, produce fruit. However, in 2004 multiple plants in one Fort Lauderdale neighborhood were noted to produce fruit. One large plant owned by the author produced 26 capsules.

The flowers of Cattleya sensu lato are of the "gullet-type", and are thought to be melittophilous (bee pollinated) (Dressler 1981, van der Cingel 2001), but the pollinators of G. skinneri have not been determined with certainty, even in its native area. A pollination study was done in Costa Rica and a number of small bees were seen visiting the flowers but none were observed to remove the pollinaria (Mora-Monge \& Valerio-Gutiérrez 1988). In that study bees in the genus Euglossa were seen flying near the flowers but none were observed to visit the flowers. A prime suspect to be the pollinator of G. skinneri in Florida was the newly naturalized Euglossa viridissima Friese (Skov \& Wiley 2005, Pemberton \& Wheeler 2006). This bee was first observed in southern Florida in June 2003 and had become locally abundant although patchily distributed in Fort Lauderdale by 2004 (Pemberton \& Wheeler 2006). This bee is native to Mexico and Central America (Roubik \& Hanson 2004) and is sympatric with G. skinneri. Orchid bees (Euglossa species and other euglossine bees) are best known as pollinator mutualists of perfume orchids which are mostly species of the Neotropical orchid tribes Catasetinae, Stanhopeinae, and Lycastinae. Male orchid bees pollinate the flowers while gathering their fragrance compounds to use in their courtship (Dodson et al. 1969, Dressler 1982, Williams 1982, Eltz et al. 2005) Both male and female euglossine bees seeking nectar are pollinators of Cattleya species and their relatives (van der Pijl \& Dodson 1966, van der Cingel 2001). The primary purpose of this study was to learn if E. viridissima is a pollinator of G. skinneri in southern Florida. 


\section{Methods}

BREEDING SYSTEM: To obtain insights into the breeding system of G. skinneri in the absence of the orchid bee or other pollinators, a single medium sized plant with seven inflorescences was manipulated. To determine the possibility of autogamy, two inflorescences each with nine flowers were enclosed in mesh bags (constructed of bridal veil cloth with $1 \mathrm{~mm} \times 1 \mathrm{~mm}$ holes) for the entire blooming period. To determine self compatibility, nine flowers in four inflorescences were hand pollinated with pollinaria taken from nine different flowers in the same four inflorescences but not their own. A single inflorescence with six flowers was left unmanipulated except for being tagged. The plant was kept inside a screened porch with filtered western light to isolate it from potential pollinators. Fruit formation, postmanipulation appearance and longevity for all flowers were recorded. Eight flowers from untreated inflorescences were dissected to visually determine if floral nectar was present.

Timed Exposures: Three potted G. skinneri plants were exposed to insect visitors; one large plant with 100 flowers, and two small plants, one with 12 total flowers in two inflorescences, and other also with two inflorescences with $c a .12$ flowers. All three plants were placed inside an outdoor screened swimming pool enclosure when flower buds began to develop. Shortly after the plants began to flower, they were moved to a Fort Lauderdale, Florida garden where the orchid bee is common, for timed exposures. For the large plant, eight exposures from one to two hours long were made during its entire flowering period from February 26 to March 27, 2006. For the small plants, single exposures were made on March 27 and April 10. Prior to an exposure on March 2, 10 flowers from 10 different inflorescences of the same large plant used for the pollinator exposures, with ca. 100 flowers, were dissected to look for floral nectar. The date, time of day, and time amount of individual exposures are given in Table 1. Flower visitors were noted, identified and observed to determine their orientation to the flowers and potential contact with the pollinaria and stigmas.

Two other related orchids were also briefly exposed. A single plant of Cattleya mossiae Hooker was exposed on from 7:00-9:00 am on March 13
2006 concurrently with G. skinneri and placed ca. 3 $\mathrm{m}$ from it. Guairanthe patinii (Cogn.) Dressler \& W.E. Higgins, a congeneric species very similar to $G$. skinneri native from Costa Rica to northern South America and Trinidad (Dressler 2005), which flowers in the autumn instead of spring, was exposed from 7:30 to 8:30 am on November 8 and from 11:00 am to 12:00 pm on November 10, 2006.

\section{Results}

Breeding System: None of the 18 flowers in two bagged inflorescences set fruit indicating that G. skinneri is probably not autogamous. All nine flowers hand pollinated with pollinia from the same plant set fruit indicating self compatibility.

FLOWER LONGEVITY AND NECTARIES: All flowers that were pollinated and those from which pollinaria were removed closed their labial flower tubes the day following treatment and had wilted by the fifth day after treatment. By contrast, flowers treated only by being enclosed in bags did not wilt until two weeks following treatment, and the unmanipulated, newly opened flowers lasted for three weeks. A floral nectary chamber was detected deep within the pedicel but was dry indicating that the flowers lack floral nectar in all 18 dissected flowers. The flowers however have extrafloral nectaries at the tops of the ovaries just behind the sepals, and at the base of the ovary, and droplets of nectar are apparent in both. In pollinated flowers, the secretion of nectar from extafloral nectaries on the ovaries behind the sepals increased secretion, while extrafloral nectaries on flowers from which pollinaria were removed ceased nectar production. The average ovarial extrafloral nectar volume from five bagged flowers was about one microliter compared to almost 13 microliters from the same nectaries on developing fruit 12 days after pollination. Undetermined species of ants were observed collecting nectar from the swelling ovaries of pollinated flowers.

\section{TIMED EXPOSURES:}

Visitors -- During the more than 13 hours of timed exposures (which averaged 80. 5 minutes), six butterfly species occasionally probed the flowers with their proboscises, each during single visits but none removed pollinaria. These included a giant swallowtail [Papillo crephontes (Cramer)]: one flower; a 
PEMBerton - Euglossine bee pollination of Guarianthe skinneri

463

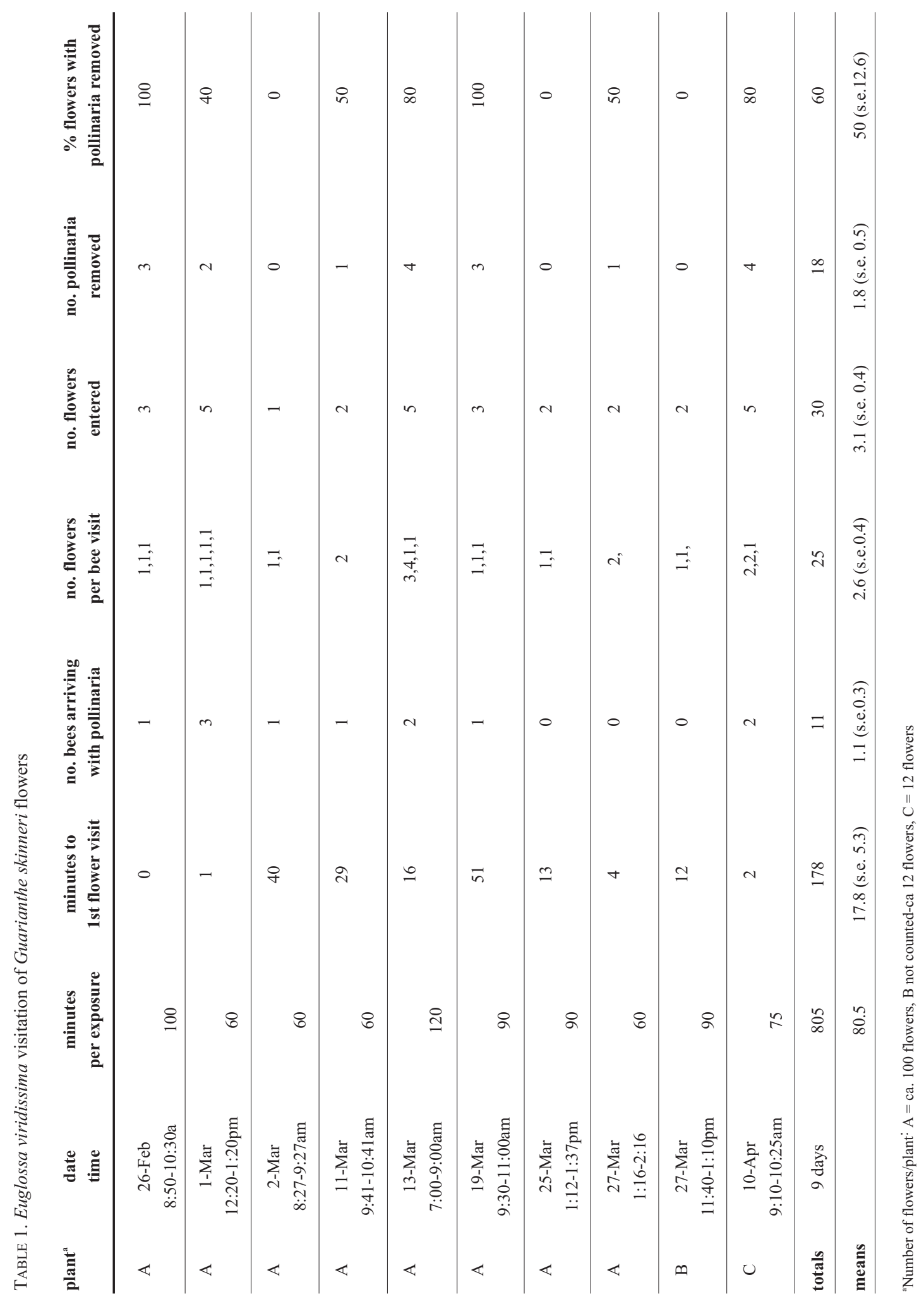

LANKESTERIANA 7(3), diciembre 2007. C Universidad de Costa Rica, 2007. 
monarch [Danaus plexippus (L.)]: five flowers; a ruddy daggerwing [Marpesia petreus (Cramer)]: four flowers; a Gulf fritillary [Agraulis vanillae (L.)]: one flower; a monk skipper [Asbolis capucinus (Lucas)]: two flowers; and another large unidentified skipper (Hesperiidae): two flowers. The only other visitor to G. skinneri flowers was the orchid bee E. viridissima, which was seen in all ten exposures on nine different days (Table 1).

Euglossa viridissima approached flowers of exposed plants on 43 occasions or, on average, once every 26 minutes. During more that half of these appearances, the bees entered flowers. Bees entered flowers during all nine exposure dates and entered from 2 to 5 flowers per average 80 minute exposure and a mean of 3.1 (s.e. 0.5) flowers. In all, 25 bees were observed to enter 31 flowers. The bees usually discovered the exposed plants soon after they were taken from the screen house and placed in the garden. Bees appeared and entered flowers as quickly as within the first minute or two of exposure. In most cases bees discovered the exposed plants but entered them a little later. The time of the first approach after an orchid plant was exposed ranged from 1 to 26 minutes and averaged 9 minutes. The time of the first flower visit ranged from 1 minute to 51 minutes and averaged (mean) 17.8 (s.e 5.3) minutes. Guarianthe skinneri has a narrow labellum tube and when E. viridissima visits the flower, it first lands on the limb of the labellum and then crawls into the tube. When the bee exits, it backs out depositing pollinia and/or picking up the pollinaria in the process. Bees removed pollinaria from 18 of the $31(58 \%)$ visited flowers. Pollinaria were removed during seven of the nine exposure periods and a median of 1.5 (s.d. 1.6) pollinaria were removed per exposure period. Eleven bees appearing and approaching plants during seven of the nine watches bore G. skinneri pollinaria glued to their faces (Figure 1). Of the 18 pollinaria that I observed the bees remove during their visits to flowers, 11 $(61 \%)$ were obtained from the first flower visited and $6(33.3 \%)$ on the second flower visited. Of the 25 bees that entered flowers, $17(68 \%)$ visited only a single flower before leaving the plant. The other seven bees entered multiple flowers during visits: 4 bees visited two flowers, two bees visited three flowers, and one bee visited four flowers. The lack of a nectar reward apparently induced most bees to

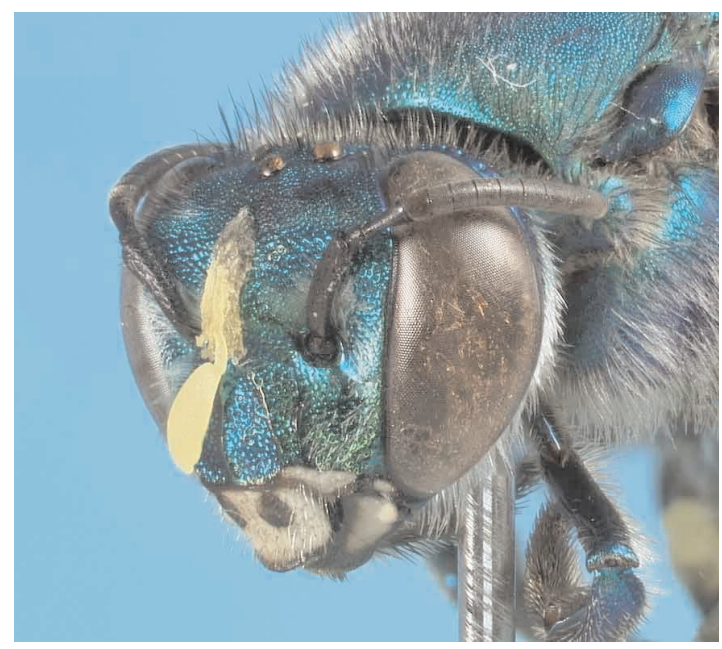

FIgURE 1. Photograph of a specimen of an orchid bee (Euglossa viridissima) which visited a Guarianthe skinneri flower. Note part of a pollinaria from the orchid attached to its face.

quickly leave the plant. Rapid departure might have been due also to the placement of the pollinaria on the bee's face. When some bees had pollinaria applied to them, they flew from the flower and landed nearby (within a meter or two) and tried to remove the offending pollinaria with their feet. I observed 4 bees try to remove pollinaria but saw only bee that was successful. Although no deposition of pollinia was clearly observed during the timed exposures, several flowers on the large exposed plant set fruit. The large number of flowers on the plants coupled with the extremely rapid flight of E. viridissima made it difficult to observe every flower visit. The bees sometimes approached the plants from the side opposite the observer and visited flowers on that side could not be seen. Many of the orchid bees appeared to be aware of the observer who sat ca. three meters from the plant, and flew quickly from the plant if the observer moved or approached the plant, behavior that made photography difficult. Male E. viridissima can be more readily approached while they gather fragrance from perfume orchids or eugenol baits. Bees gathering nectar and pollen are also more approachable than those visiting the unrewarding $G$. skinneri.

Although it was difficult to determine the gender of these rapidly moving bees, many of the visiting E. viridissima were females because they frequently 
visited and buzzed nearby flowers of Solanum pyracantha Smith, S. wendlandii Hook.f., and Lycianthes rantonnei (Carriere) Bitter, both prior to and after visiting G. skinneri.

Two flowers of the exposed Cattleya mossiae were visited by $E$. viridissima. One bee entered a flower and exited with the pollinaria glued to the dorsal surface of its thorax. The other bee first visited a G. skinneri flower, picked up a pollinaria and then entered a flower of $C$. mossiae. The bee was captured as it left the flower with the G. skinneri pollinaria still attached to it. Guarianthe patnii was not visited during the one hour exposure on November 8, but during the one hour exposure on November 10 two $E$. viridissima entered four flowers but did not remove pollinaria.

\section{Discussion}

Although E. viridissima was not observed to deposit pollinia in any G. skinneri flowers, the bee is probably a pollinator of the species in Florida. Bees were observed to visit many flowers and often quickly after the flowers'exposure. The bees visited flowers relatively frequently and removed many pollinaria, especially when one considers that the 13 plus hours of exposures and watches represented only a little more than one day of the 14-21 day flowering period. Further, E. viridissima was the only bee species to visit G. skinneri, which like other Cattleya type flowers, is considered to be bee pollinated (Dressler 1981, van der Cingel 2001). The only other visitors during the exposure periods were butterflies which probed the flowers to try to locate nectar but did not remove pollinaria. A flower visitor that removes and bears the pollinaria is likely to be the legitimate pollinator of the plant (Dressler 1976, 1981).

It is shown that Guarianthe skinneri is both self compatible and nectarless. Mora-Monge and Valerio-Gutiérrez (1988) also confirmed the absence of floral nectar in this orchid. About one third of orchid species offer no nectar reward, even though nectar rewarding orchids consistently produce higher fruit set (Neiland \& Wilcock 1998, Tremblay et al. 2005, Jersáková et al. 2006). Some authors (Boyden 1982, Ackerman 1986) have speculated that the high cost of nectar production could have favored the selection of nectarless mutants.
The lack of a nectar reward has been thought to promote outcrossing (Dressler 1981, Jersáková et al. 2006). Guarianthe skinneri produces large quantities of extrafloral nectar from glands located on the outer surfaces of flowers (also documented by Mora-Monge \& Valerio-Gutérrez 1988, and Damon \& Pérez-Soriano 2005). Nectar production from these glands ceases quickly after pollinaria removal, but increases dramatically in pollinated flowers especially during fruit formation. Extrafloral nectar has been shown by many studies to be a reward for ant mutualists, which reduce insect herbivore damage to plants with extrafloral nectaries (Koptur 1992). Extrafloral nectaries commonly occur in orchid inflorescences but are little studied. Almeida and Figueiredo (2003) concluded that a Camponotus ant species protects the reproductive structures of Epidendron denticulatum (Jacq.) in Brazil. Damon and Perea-Soriano (2005) reported 19 species of ants were associated with the inflorescences of nine orchid species in Mexico. Among the detected ants, were Crematogaster and Camponotus spp. visiting the extrafloral nectaries of G. skinneri. Extrafloral nectar in G. skinneri probably functions first to protect the flowers and then the developing fruit. The ability to produce copious amounts of extrafloral nectar on flowers and developing fruits suggests that the loss of floral nectar in G. skinneri is probably not due to the high cost for nectar production. The visitation pattern of E. viridissima to G. skinneri flowers, however, supports the idea that the lack of a nectar reward reduces geitonogamy and promotes outcrossing. Sixty-eight percent $(17 / 25)$ of the bees visiting flowers left the plant after visiting just one flower.

Guarianthe skinneri's nectarless flowers employ food deception pollination. This is indicated by the many female bees entering the flowers and the probing of the flowers by butterflies. The labial tube of $G$. skinneri resembles in a general way the many nectar-rewarding, gullet-type flowers which E. viridissima routinely visits in gardens and parks in southern Florida. These include species of Tabebuia and Tecoma (Bignoniaceae), Allamanda, Thevetia, Mandevilla and Stemmadenia (Apocynaceae) and Ruellia (Acanthaceae). These plants, like the E. viridissima and G. skinneri, are native to tropical America. Johnson et al. (2003) demonstrated that the pollination success in a food 
deception orchid was enhanced when it co-occurred with nectar rewarding plants.

It is very likely that $E$. viridissima is also a pollinator of G. skinneri in its native range including Costa Rica both because of the nearly complete geographical overlap of both species and the attractiveness of G. skinneri to this bee. Also as noted above, Mora-Monge and Valerio-Gutiérrez (1988) observed bees of the genus Euglossa flying near the flowers. The visitations of E. viridissima to both $G$. patinii and C. mossiae in only limited exposures suggests that the bee may be a pollinator of Guarianthe species and some Cattleya species with narrow labial tubes. A bee's visitation of C. mossiae while carrying pollinaria of G. skinneri suggests that $E$. viridissima could be an agent of hybridization between these and other related, morphologically similar, concurrently flowering orchids. Guarianthe skinneri is known to produce hybrid swarms with G. aurantiaca (Bateman ex Lindley) Dressler \& W.E. Higgins in areas of sympatry from Mexico to Nicaragua (Dressler \& Higgins 2003). Although $G$. aurantiaca is believed to be normally pollinated by hummingbirds, bees are the likely agents of natural hybridization because flowers of G. skinneri are ill adapted for hummingbird visitors but small bees should have no problem in entering flowers of G. aurantiaca (van der Pijl \& Dodson 1966, van der Cingel 2001).

Euglossa viridissima's pollination of G. skinneri in Florida could facilitate the orchid's naturalization. Only a handful of orchid species are naturalized in Florida (Wunderlin \& Hansen 2003, Brown 2002), despite their commonness as ornamental plants. The lack of naturalization may be due to the absence of the appropriate pollinators, or perhaps the absence of suitable mycorhizae. Most of the naturalized orchids in Florida appear to self pollinate or otherwise be autogamous; i.e., Oeceoclades maculata (Lindley) Lindley, Phaius tankervilleae (Aiton) Blume, Spathoglottis plicata Blume, and Zeuxine strateumatica (L.) Schlechter. But Ackerman (2007), discussing weedy orchids and citing Sun (1997), indicates that weedy orchids have the complete spectrum of breeding systems. An interesting correlate of autogamy in some of Florida's naturalized orchids is that many orchids that occur naturally in Florida and also in parts of tropical America, are represented in Florida by self pollinating forms or autogamous forms (van der Pij1 \& Dodson 1966). Selfing triandrous forms occur in Florida for some widespread species such as Prosthechea cochleata (L.) W.E. Higgins and agamospermy in races of Sacoila lanceolata (Aublet) Garay (Catling 1987).

Guarianthe skinneri tolerates dry winters of southern Florida because it is adapted to resist an annual dry season in its native range (Mario Blanco, pers. com.). Although it survives cool periods during southern Florida when temperatures drop below $10 \mathrm{C}$, the greatest limitation to this plant's ability to persist in southern Florida is the region's infrequent freezes. The last freeze in Ft. Lauderdale, where the study was done occurred in 1989 when the temperature dropped to $-1.1 \mathrm{C}$. at the nearby Ft. Lauderdale-Hollywood Airport (www.weather.gov). But between 1912 and 1985 freezes with temperatures falling below $-1.1 \mathrm{C}$ occurred 5 times (www.weather.gov).

Euglossa viridissima's visitation of G. skinneri and some Cattleya species (and potentially many other cultivated orchids) in Florida may be undesirable from the perspective of commercial and amateur growers because either pollination or pollinaria removal causes the flowers to wilt one day later. Part of the appeal and commercial value of these orchids is the longevity of their flowers, which could be strongly reduced by visiting $E$. viridissima bees. Pollination and pollinaria removal by this bee could also interfere with breeding work with plants in orchid houses accessible to the bee. Visited Cattleya species and hybrids with larger diameter floral tubes will probably be unaffected because $E$. viridissima is too small to contact their pollinaria. This was observed when male E. viridissima bees visited the flowers of C. quadricolor Lindley and worked intensively collecting fragrance from the inner walls of the labial tube but failed to contact the column (Pemberton unpublished data). Euglossine bees reportedly get stuck and die on the large stigma of some large flowered Cattleya hybrids cultivated in tropical America (van der Cingel 2001).

The environmental consequences of the naturalization of E. viridissima may be significant both because of its abundance in southern Florida and its visitation to flowers of more than a 100 species of plants (Pemberton \& Wheeler 2006, Pemberton unpublished data). For instance, Euglossa viridissima is pollinat- 
ing the resin reward flowers of the euphorbiaceous vine Dalechampia scandens L., a Tropical American plant which has also recently naturalized in southern Florida (Pemberton \& Liu, in press). Because $E$. viridissima is abundant and distinctive, being the only orchid bee present in Florida, compared to many similar green Euglossa species in most tropical American habitats, its field behavior can be more readily and confidently observed and understood. And as with this study with the bee and G. skinneri, this understanding can extend to Tropical America.

ACKNOWLEDGEMENTS. Mario Blanco kindly provided literature, translated Mora-Monge and Valerio-Gutiérrez (1988), and provided a helpful review of the manuscript. Paul Skelley took the photograph of the orchid bee using the Florida Department of Agriculture and Consumer Service's photomontage system. This research was conducted independently by the author, and was not supported by nor conducted as part of the USDA Agricultural Research Service mission.

\section{Literature Cited}

Ackerman, J.D. 1986. Mechanisms and evolution of fooddeceptive pollination systems in orchids. Lindleyana 1 : 108-113.

Ackerman. J.D. 2007. Invasive orchids: weeds we hate to love? Lankesteriana 7: 19-21.

Almeida, A.M. \& R.A. Figueiredo. 2003. Ants visit nectaries of Epidendron dentriculatum (Orchidaceae) in a Brazilian rainforest: effects on herbivory and pollination. Brazil. J. Biol. 63: 551-558.

Bechtel, H., P. Cribb \& E. Launert. 1992. The manual of cultivated orchid species. $3^{\text {rd }}$ Ed. The MIT Press, Cambridge, Massachusetts, U.S.A.

Boyden, T.C.1982. The pollination biology of Calypso bulbosa var. americana (Orchidaceae): initial deception of bumblebee visitors. Oecologia 55: 178-184.

Brown, P.M. 2002. Wild orchids of Florida. University Press of Florida, Gainesville.

Catling, P.M.1987. Notes on the breeding systems of Sacoila lanceolata (Aubet) Garay (Orchidaceae). Ann. Missouri Bot. Gard. 74: 58-68.

Damon, A. \& M.A. Pérez-Soriano. 2005. Interaction between ants and orchids in the Soconusco region, Chiapas, Mexico. Entomotropica 20: 59-65.

Dodson, C.H., R.L. Dressler, H.C. Hills, R.M. Adams \& N.H. Williams. 1969. Biologically active compounds in orchid fragrances. Science 164: 1243-1249.
Dressler, R.L. 1976. How to study orchid pollination without any orchids. Pp. 534-537 in: Senghas, K. (ed.) Proceedings of the eight world orchid conference. Frankfurt, German Orchid Society.

Dressler, R.L. 1981. The Orchids: Natural History and Classification. Harvard University Press, Cambridge.

Dressler, R.L. 1982. Biology of the orchid bees (Euglossini). Ann. Rev. Ecol. Syst. 13: 373-394.

Dressler, R.L. 2005. Guarianthe. Pages 348-363 in: F. Pupulin (ed.), Vanishing Beauty: Native Costa Rican Orchids, Volume 1 (Acianthera-Kegeliella). Editorial de la Universidad de Costa Rica, San José.

Dressler, R.L. \& W.E. Higgins. 2003. Guarianthe, a generic name for the "Cattleya" skinneri complex. Lankesteriana 7: 33-38.

Eltz, T.A., A Sager \& K. Lunau. 2005. Juggling with volatiles: exposures of perfumes by displaying male orchid bees. J. Comp. Phys. A. 191: 575-581.

Janzen, D.H., P.J. DeVries, M.L. Higgins \& L.S. Kimsey. 1982. Seasonal and site variation in Costa Rican euglossine bees at chemical baits in lowland deciduous and evergreen forests. Ecology 63: 66-74.

Jersáková, J., S.D. Johnson and P. Kindlmann. 2006. Mechanisms and evolution of deceptive pollination in orchids. Biol. Rev. 81: 219-235.

Johnson, S.D., C.I. Peter, L.A. Nilsson, and Jon Agren. 2003. Pollination success in a deceptive orchid is enhanced by co-occurring rewarding magnet plants. Ecology 84: 2919-2927.

Koptur, S. 1992. Extrafloral nectary-mediated interactions between insects and plants. In E. Bernays (ed.), Insectplant interactions, vol. IV, 81-129. CRC Press, Boca Raton, Florida.

Mora-Monge, D.E. and C.E. Valerio-Gutiérrez. 1988. Polinización y producción de frutos en la Guaria Morada (Cattleya skinneri, Orchidaceae) en Costa Rica. Orquideología 17: 242-251.

Neiland, M.R. and C. Wilcock. 1998. Fruit set, nectar reward, and rarity in the Orchidaceae. Amer. J. Bot. 85: 167-1671.

Pemberton, R.W. and G.S. Wheeler. 2006. Orchid bees don't need orchids: Evidence from the naturalization of an orchid bee in Florida. Ecology 87: 1995-2001.

Pemberton, R.W. and H. Liu. in press. Naturalization of Dalechampia scandens in southern Florida. Carib. J. Sc.

Roubik, D.W. \& P.E. Hanson. 2004. Orchid bees of tropical America, biology and field guide. Instituto Nacional de Biodiversidad, San Jose, Costa Rica.

Sun, M. 1997. Genetic diversity in three colonizing orchids with contrasting mating systems. Amer. J. Bot. 84: 224-232. 
Tremblay, R.L., J.D. Ackerman, J.K. Zimmerman \& R.N. Calvo. 2005. Variation in sexual reproduction in orchids and its evolutionary consequences: a spasmodic journey to diversification. Biol. J. Linnean Soc.: 84: 1-54.

van der Cingel, N.A. 2001. An atlas of orchid pollination: America, Africa, and Australia. A. A. Balkema, Rotterdam, Netherlands.

van der Pijl, L. \& C. Dodson. 1966. Orchid flowers: their pollination and evolution. Fairchild Botanical Garden and the University of Miami Press, Coral Cables.

Williams, N.H. 1982. The biology of orchids and euglossine bees. Pages 119-171, In J. Arditti (ed.), Orchid Biology: Reviews and Perspectives, II. Cornell University Press, Ithaca.

Wunderlin, R.P. and B.F. Hansen. 2003. Guide to the vascular plants of Florida. University Press Florida, Gainesville. 